\title{
Caesarean myomectomy - a safe procedure: A retrospective case controlled study
}

\author{
Alexander T. Owolabi, Oluwafemi Kuti, Olabisi M. Loto, \\ Oluwafemiwa N. Makinde, Adebanjo B. Adeyemi \\ Departments of Obstetrics, Gynaecology \& Perinatology, College of Health Sciences, \\ Obafemi Awolowo University, Ile-Ife, Osun State, Nigeria.
}

\begin{abstract}
Objective(s): The aim of the study is to determine whether myomectomy at the time of caesarean section leads to increase incidence of intrapartum and postpartum complications.

Methods: Fourteen women, with uterine fibroids in pregnancy who were treated by caesarean myomectomy between January 2001 and June 2007, were compared retrospectively with fourteen women, without uterine fibroids who had routine caesarean section during the same period. Myomectomy for all types of myoma was performed at caesarean section after the delivery of the baby. Haemorrhage was controlled with the use of Foleys catheter tourniquet and high dose oxytocin infusion. The cases and control were analysed for age of the patient, parity, pre and post-operative haematocrit levels, duration of operation, blood loss, blood transfusions, and incidence of postpartum fever.

Results: Caesarean myomectomy resulted in the mean blood loss of $589 \mathrm{ml}$ (range 300-1300 ml) compared with $518 \mathrm{ml}$ (range 350-850 $\mathrm{ml}$ ) in the control group $(\mathrm{p}=0.376)$. The mean duration of operation was longer in the cases of caesarean myomectomy (66.8 mins) than those of the controls (56.4 mins). There were no significant differences between the two groups in the incidence of intraoperative haemorrhage, the need for blood transfusion, post partum fever, and length of hospital stay.

Conclusions: This study shows that myomectomy during caesarean section is a safe procedure in experienced hands and is not as dangerous as generations of obstetricians have been trained to believe. Further research is necessary to establish the cost effectiveness of the procedure.
\end{abstract}

Key words: myomectomy, cesarean section, hemorrhage

\section{Introduction}

Myomectomy at the time of caesarean section has traditionally been discouraged due to the theoretical risks of intractable haemorrhage which may require hysterectomy and increased postoperative morbidity ${ }^{1}$. However a new frontier in surgical practices has been encountered with various reports of successfully performed myomectomy during the time of caesarean section and in pregnancy ${ }^{2-7}$. The place of myomectomy at caesarean section is still however limited to few experienced units and not as a routine procedure ${ }^{8}$. Fibroids affect pregnancy and delivery in several ways such as abdominal pains, miscarriages, malpresentation and difficult deliveries depending on the size, number of fibroids, location and their relations to the placenta ${ }^{1}$. The aim of the study is to determine whether myomectomy at the time of caesarean section leads to increase incidence of intrapartum and postpartum complications.

\section{Methods}

Fourteen women, with different types of uterine fibroids in pregnancy who were treated by caesarean myomectomy between January 2001 and June 2007 at Wesley Guild Hospital Ilesa, an arm of Obafemi Awolowo University Teaching Hospital Complex

Correspondence

Dr. A.T. Owolabi, MBBS, M.Comm.H, FWACS

Department of Obstetrics, Gynecology and Perinatology, College of Health Sciences, Obafemi Awolowo University,

Ile Ife, Osun State, Nigeria, Tel: +234803715 1125.Email:alexandrerowolabi@yahoo.com 
(OAUTHC), were compared retrospectively with fourteen women, without uterine fibroids who had routine caesarean section immediately after the cases during the same period. Four of the patients were being planned for elective myomectomy before they got pregnant, two of whom had cervical cerclage and prolonged bed rest in the hospital as a result of previous mid-trimester abortions.

All the patients had general anaesthesia with endotracheal intubations. Myomectomy for all types of myoma was performed at caesarean section after the delivery of the baby. Thirteen patients were delivered by lower uterine segment incision while one patient was delivered through a classical incision because of a huge fibroid in the lower segment making the uterine cavity inaccessible. A tourniquet was then applied to the lower part of the broad ligament to compress both uterine arteries and the vessels in the infundibulo-pelvic ligament so as to achieve a bloodless operating field. The fallopian tubes were lifted and excluded from the tourniquet. Irrespective of the location of the fibroid conventional method of incision over the myomas followed by its enuncliation was employed with the dead space repaired in layers with adequate haemostasis maintained. The tourniquet was then removed with bleeding point secured further with individual stitches. High dose oxytocin infusion was started after the delivery of the baby and continued for 12-24 hours thereafter. Blood loss was estimated from the measurement of that sucked by the suction pump in addition to estimates of blood loss on the line and swabs. The number and sizes of uterine fibroids removed were documented in the operation notes. Broad spectrum antibiotics and analgesics were administered in the postoperative period.
The cases and control were analysed for age of the patient, parity, pre and post-operative haematocrit levels, duration of operation, blood loss, incidence of blood transfusion and incidence of postpartum fever. Location and number of fibroids were noted for cases.

\section{Results}

During the study period from January 2001 and June 2007 fourteen cases of caesarean myomectomy were performed. The characteristics of the cases in terms of age, parity, preoperative and postoperative haematocrit levels, and duration of operation, blood loss, location and number of fibroids are shown in table 1 . The characteristics of the controls (patient who had caesarean section without myomectomy) are shown in table II. The mean age of cases was $32.4 \pm 4.1$ years which is significantly higher than those of the controls of $27.3 \pm 4.2$ years. The mean haematocrit pre and postoperatively was $36.9 \%$ and $32.9 \%$ respectively while that of the controls were 36.1 and 32.4 respectively. The mean change in haematocrit in the caesarean myomectomy group was $4.1 \%$ while that of the caesarean section group was $3.9 \%$. Caesarean myomectomy resulted in the mean blood loss of $511 \mathrm{ml}$ (range 300-1300 ml) compared with $419 \mathrm{ml}$ (range 250$750 \mathrm{ml})$ in the control group $(\mathrm{p}=0.273)$. The blood loss of $1300 \mathrm{ml}$ occurred in a patient with a huge uterine fibroid lifting up the uterine cavity needing a classical caesarean section to deliver the baby. This was the only patient which needed blood transfusion. One patient each among the cases and control was transfused with two pints of blood each because of post operative anaemia. The mean duration of operation was longer in the cases of caesarean

Table I. Findings in patients of caesarean section with myomectomy

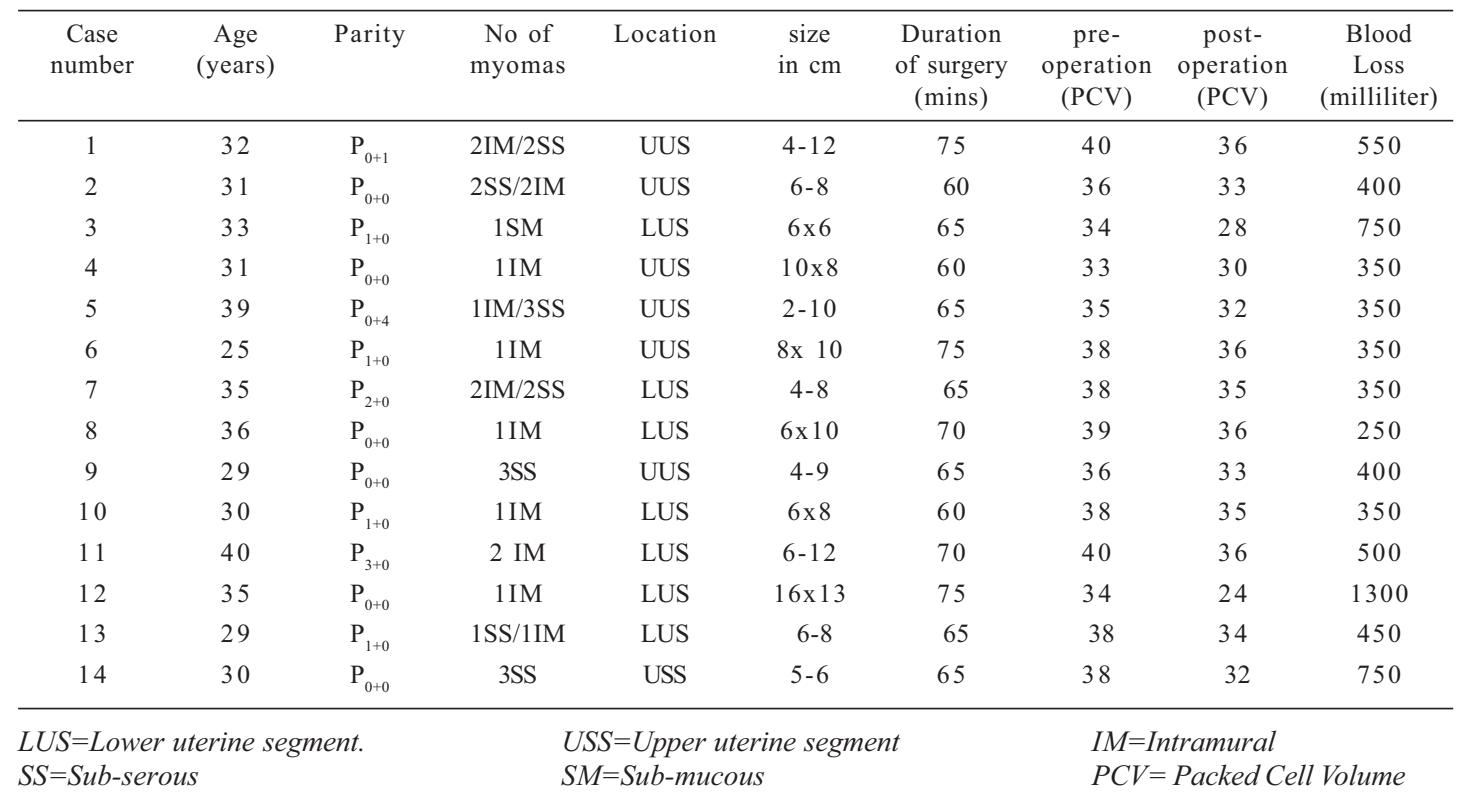


Table 2. Findings in patient with caesarean section without myomectomy

\begin{tabular}{ccccccc}
\hline $\begin{array}{c}\text { Case } \\
\text { number }\end{array}$ & $\begin{array}{c}\text { Age } \\
\text { (years) }\end{array}$ & Parity & $\begin{array}{c}\text { Duration } \\
\text { of surgery } \\
\text { (mins) }\end{array}$ & $\begin{array}{c}\text { pre- } \\
\text { operation } \\
\text { (PCV) }\end{array}$ & $\begin{array}{c}\text { post- } \\
\text { operation } \\
\text { (PCV) }\end{array}$ & $\begin{array}{c}\text { Blood } \\
\text { Loss } \\
\text { (milliliter) }\end{array}$ \\
\hline 1 & 22 & $\mathrm{P}_{1+1}$ & 55 & 35 & 32 & 400 \\
2 & 23 & $\mathrm{P}_{2+0}$ & 50 & 38 & 36 & 250 \\
3 & 29 & $\mathrm{P}_{0+0}$ & 50 & 35 & 30 & 550 \\
4 & 25 & $\mathrm{P}_{3+0}$ & 55 & 40 & 36 & 400 \\
5 & 30 & $\mathrm{P}_{0+0}$ & 60 & 32 & 24 & 750 \\
6 & 22 & $\mathrm{P}_{0+0}$ & 65 & 36 & 33 & 350 \\
7 & 31 & $\mathrm{P}_{3 z 0}$ & 55 & 35 & 32 & 300 \\
8 & 26 & $\mathrm{P}_{1+0}$ & 60 & 40 & 33 & 350 \\
9 & 24 & $\mathrm{P}_{0+0}$ & 55 & 37 & 33 & 350 \\
10 & 35 & $\mathrm{P}_{2+0}$ & 60 & 36 & 31 & 400 \\
11 & 29 & $\mathrm{P}_{0+0}$ & 60 & 34 & 30 & 600 \\
12 & 34 & $\mathrm{P}_{2+0}$ & 55 & 36 & 34 & 550 \\
14 & 25 & $\mathrm{P}_{0+0}$ & 50 & 39 & 32 & 250 \\
\hline
\end{tabular}

PCV = Packed Cell Volume

myomectomy (66.8 mins) than those of the controls (56.4 mins).

There were more intramural fibroid than subserosal fibroid and only one case of a large sub mucous fibroid located in the posterior uterine wall was encountered. The fibroid removed ranged from one to four nodules spread between the upper and lower uterine segments. None of the patient in either group required hysterectomy within six weeks of delivery. No postoperative pyrexia was encountered in either the cases or the controls. All the patients were discharged home between post operative day five and eight there was no wound infection encountered in either the cases or the controls.

\section{Discussion}

This study has clearly shown, like several other studies, that myomectomy at the time of caesarean section is a safe and feasible procedure in experienced hands $\mathrm{s}^{2-5,8-}$ ${ }^{11}$. The advantages includes the fact that interval myomectomy is avoided including the risk of a second surgery, anaesthesia and is also cost saving. Incidence of uterine fibroid in pregnancy is increasing because many women are delaying child bearing till their late thirties which is the time of greatest risk of myoma growth. Average age (32.4 years) of caesarean myomectomy patient in this study was significantly higher than that of the controls (27.3 years), in agreement with findings in another study ${ }^{2}$. Cases of unavoidable myomectomy at the time of caesarean section seems to be increasing as such obstetricians practicing where there is a high incidence of uterine fibroid in pregnancy need to keep abreast with the necessary skill to perform caesarean myomectomy $^{4-6}$.

The use of tourniquet and post delivery infusion of high dose oxytocin has prevented excessive haemorrhage during the procedure of cesarean myomectomy as observed in this study. Similar results had been documented by Kwawukume ${ }^{2}$, and Ehigieba et $\mathrm{al}^{3}$. Other techniques to minimize blood loss but was not used in this study includes bilateral uterine artery ligation and electrocautery ${ }^{12,13}$. There were no significant differences between the two groups in the incidence of intraoperative haemorrhage, the need for blood transfusion, post partum fever, and length of hospital stay in this study in agreement with findings of other researchers ${ }^{2-5,8-11}$. Caesarean myomectomy added 10.4 minutes to the duration of surgery which is similar to findings of other researchers ${ }^{2.14}$. It is worthy of note that no patient in this study like many other studies sufferer sufficient blood loss to warrant hysterectomy $2,3,5$.

It is interesting that four of our patients had been slated for elective myomectomy before they got pregnant. Indications for elective myomectomy for two of the cases were recurrent mid-trimester abortions and multiple uterine fibroids while the remaining cases were for multiple uterine fibroid in patients with unexplained infertility. All the four patients requested for elective removal of the fibroids when they were being planned for caesarean delivery. 


\section{Conclusions}

This study shows that myomectomy during caesarean section is a safe procedure in experienced hands and is not as dangerous as generations of obstetricians have been trained to believe. Further research is necessary to establish the cost effectiveness of the procedure.

\section{References}

1. Cunningham FG, Gant NF, Levenok KJ, Gilstrap LC, Hauth JC, Wenstrom KD, editors: Abnormalities of the reproductive tract. In: Williams Obstetrics 21st edition. New York: McGraw Hill; 2001:930.

2 Kwawukumen EY. Caesarean Myomectomy. Afr J Reprod Health. 2002; 6(3): 38-43.

3 Ehigiegba AE, Anda, AB, Ojobo SI. Myomectomy during Caesarean Section. Int. J. Gynecol Obstet. 2001; 75:21-25.

4 Agboghoroma CO, Efetie ER and Umezurlike AC. Unavoidable Caesarean Myomectomy: A Case Report. Trop J Obstet Gynaecol. 2005; 22(1): 8182.

5 Sudhir A. and Sebanti G. Cesarean myomectomyA study of 14 cases. J Obstet Gynecol India. 2006; 56(6):486-488.

6 Ande A.B. Ehigiegba A.E. and Umeora O.U. Repeat myomectomy at caesarean section. Arch Gynaecol Obstet. 2004; 270 (4):296-8.
7 Bolaji I.I., Rafla N.M. and Mylotte M.J. Classical caesarean section through the posterior uterine wall. Ir J Med Sci. 1992; 161 (2):46-7

8 Omigbodun A.O. and Fawole A.O. Commentary: Myomectomy During Pregnancy and Delivery: Is it Safe? Trop J Obstet Gynaecol. 2005; 22 (1):1-3.

9 Roman AS, Tabsh KMA. Myomectomy at time of cesarean delivery; a retrospective cohort study. BMC Pregnancy and Child birth 2004; 4:14-7.

10 Omar SZ, Sivanesaratnam V, Damodaran P. Large lower segment myoma-myomectomy at lower segment caesarean section a report of two cases. Singapore Med J 1990; 40:109-10.

11 Anita K, Seema M and Richa P. Caesarean myomectomy. J Obstet Gynecol India. 2007; 57 (2):124-127.

12 Sapmaz E, Celik H and Altungul A: Bilateral ascending uterine artery ligation vs. tourniquet use for haemostasis in cesarean myomectomy. A comparison. J Reprod Med 2003, 48:950-4.

13 Cobellis L, Florio P, Stradella L, Lucia ED, Messalli EM, Petraglia F and Cobellis G: Electro-cautery of myomas during caesarean section - two case reports. Eur J Obstet Gynecol Reprod Biol 2002, 102:98-9.

14 Hsieh T.T. Cheng B.J. Liou J.D. and Chiw T.H. Incidence of myomectomy in caesarean section. Chaggeng Yi Xue Za Zhi 1989; 12(1):13-20. 